\title{
Solar City Indicator: A Methodology to Predict City Level PV Installed Capacity by Combining Physical Capacity and Socio-economic Factors
}

\author{
James Gooding*, Holly Edwards, Jannik Giesekam and Rolf Crook
}

Energy Research Institute, University of Leeds, LS2 9JT, UK

*Corresponding Author: Tel +44 1133432556

Email addresses: pmhae@leeds.ac.uk (Holly Edwards),pmjjg@leeds.ac.uk (Jannik Giesekam), ee09jg@leeds.ac.uk (James Gooding), R.Crook@leeds.ac.uk (Rolf Crook)

\section{Abstract}

Shifting to renewable sources of electricity is imperative in achieving global reductions in carbon emissions and ensuring future energy security. One technology, solar photovoltaics (PV), has begun to generate a noticeable contribution to the electricity mix in numerous countries. However, the upper limits of this contribution have not been explored in a way that combines both building-bybuilding solar resource appraisals with the city-scale socio-economic contexts that dictate PV uptake. This paper presents such a method, whereby a 'Solar City Indicator' is calculated and used to rank cities by their capacity to generate electricity from roof-mounted PV. Seven major UK cities were chosen for analysis based on available data; Dundee, Derby, Edinburgh, Glasgow, Leicester, Nottingham and Sheffield. The physical capacity of each city was established using a GIS-based methodology, exploiting digital surface models and LiDAR data, with distinct methodologies for large and small properties. Socio-economic factors (income, education, environmental consciousness, building stock and ownership) were chosen based on existing literature and correlation with current levels of PV installations. These factors were enumerated using data that was readily available across each city. Results show that Derby has the greatest potential of all the cities analysed, as it offers both good physical and socio-economic potential. In terms of physical capacity it was seen that over a 15 year payback period there are two plateaus, showing a marked difference in viability between small and large PV arrays. It was found that both the physical and socio-economic potential of a city are strongly influenced by the nature of the local building stock. This study also identifies areas where policy needs to be focused in order to encourage uptake and highlights factors limiting maximum PV uptake. While this methodology has been demonstrated using UK cities, it is equally applicable to any country where city data is available.

\section{Keywords}

Photovoltaics; Renewable Energy; GIS; potential quantification; resource appraisal 


\section{Introduction}

With an increased effort to reduce global $\mathrm{CO}_{2}$ emissions, as well as ensuring countries become more energy secure, solar PV technology is seeing increasing growth worldwide. In some cases this has taken the form of large scale solar farms; however in many countries the focus has been on a more decentralised microgeneration approach. One such country is the UK, which forms the focus for this particular study.

Microgeneration has the potential to become a significant contributor to the UK's energy mix and could form an important part of meeting the UK's 15\% renewable energy target by 2020 set by the European Commission. Of all the microgeneration technologies available, solar photovoltaics (PV) has shown the most potential to meet energy demand to date. By the end of August 2012 solar PV represented over $90 \%$ of the $1.4 \mathrm{GW}$ of microgeneration capacity installed under the UK Feed-inTariff (FiT) scheme accounting for over 370,000 installations (DECC, 2012a).

In the past the Government has supported the solar PV industry through grant support, such as the UK PV Domestic Field Trials and the Major Photovoltaic Demonstration Programme (Jardine and Bergman, 2009). In April 2010 the Government moved away from such schemes and opted for a Feed-in Tariff (FiT) system, which had already seen success in a number of other countries, particularly Germany. Such a mechanism results in the generator receiving a payment for each $\mathrm{kWh}$ of electricity from their PV installation (Table 1) whether exported to the grid or used on the property. The result has been a trebling in the number of UK PV installations in the past year (see Figure 1). However, the FiT scheme has seen some significant changes since December 2011 under a three stage consultation by the UK government. The changes to the rates of FiT for solar PV as a result of this consultation can be seen in

Table 1. In addition to these rate changes, a new degression mechanism has also been implemented from 1 November 2012, which has introduced new tariff rates more frequently at three month intervals and is determined by the rate of deployment from a baseline of 3.5\% (DECC, 2012c). 
1500 MW Capacity Installed Under FiT

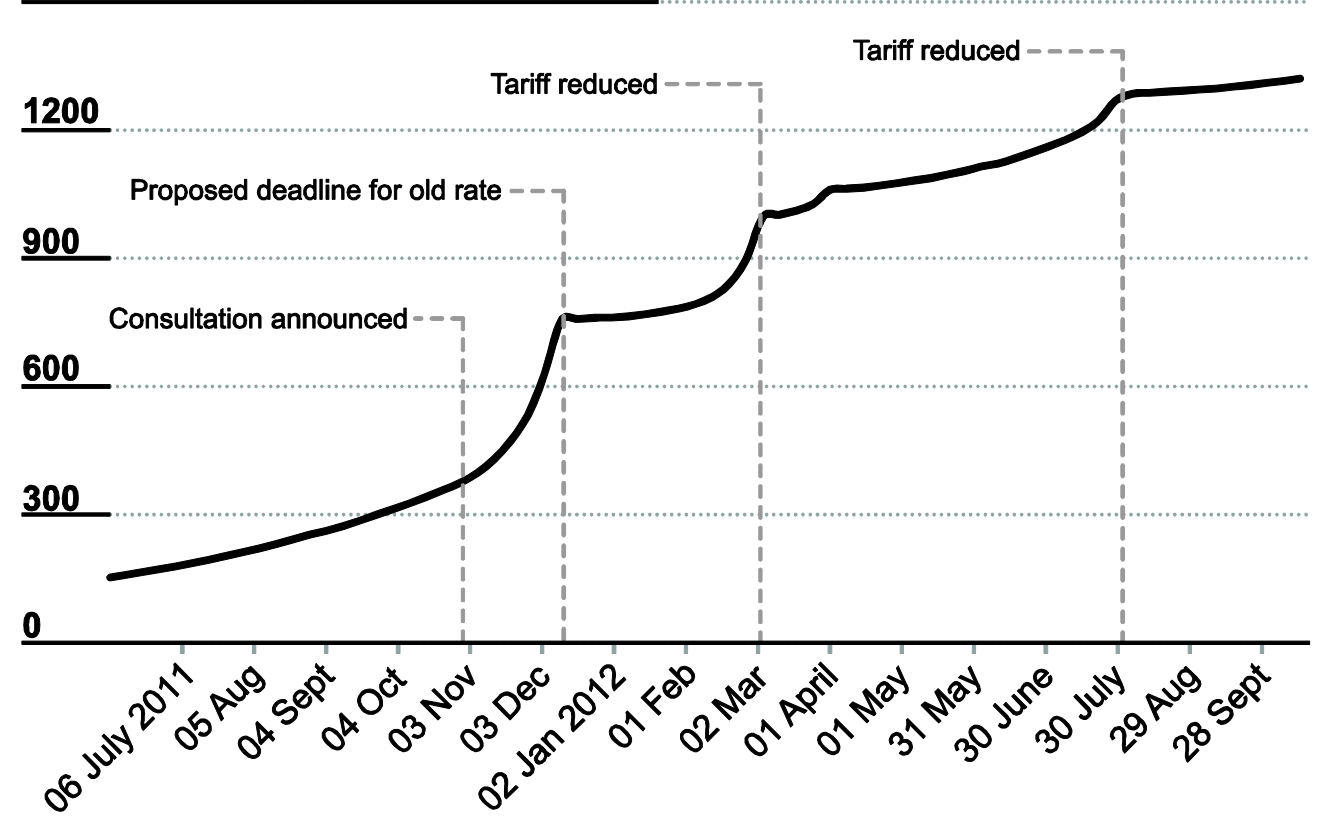

Figure 1: Installed capacity of solar PV under the FiT scheme between June 2011 and October 2012 (DECC, 2012a)

Table 1: Changes to FiT rates for solar PV - all rates are p/kWh (DECC, 2012b)

\begin{tabular}{|l|c|c|c|c|c|}
\hline \multicolumn{1}{|c|}{ Band } & Rate & Rate 3 & \multicolumn{3}{|c|}{ FiT rates from 1 August 2012 } \\
\cline { 4 - 6 } & $\begin{array}{c}\text { prior to 3 } \\
\text { March } \\
\mathbf{2 0 1 2}\end{array}$ & $\begin{array}{c}\text { March to 1 } \\
\text { August 2012 }\end{array}$ & $\begin{array}{c}\text { Standard } \\
\text { generation } \\
\text { tariff }\end{array}$ & $\begin{array}{c}\text { Multi- } \\
\text { installation } \\
\text { tariff }\end{array}$ & $\begin{array}{c}\text { Lower tariff (if energy } \\
\text { efficiency requirement } \\
\text { not met) }\end{array}$ \\
\hline 4kW (new build) & 37.8 & 21.0 & 16.0 & 14.4 & 7.1 \\
\hline 4kW (retrofit) & 43.3 & 21.0 & 16.0 & 14.4 & 7.1 \\
\hline$>4-10 \mathrm{~kW}$ & 37.8 & 16.8 & 14.5 & 13.05 & 7.1 \\
\hline$>10-50 \mathrm{~kW}$ & 32.9 & 15.2 & 13.5 & 12.15 & 7.1 \\
\hline$>50-100 \mathrm{~kW}$ & 19.0 & 12.9 & 11.5 & 10.35 & 7.1 \\
\hline$>100-150 \mathrm{~kW}$ & 19.0 & 12.9 & 11.5 & 10.35 & 7.1 \\
\hline$>150-250 \mathrm{~kW}$ & 15.0 & 12.9 & 11.0 & 9.9 & 7.1 \\
\hline$>250 \mathrm{~kW}-5 \mathrm{MW}$ & 8.5 & 8.5 & 7.1 & $\mathrm{~N} / \mathrm{A}$ & N/A \\
\hline Stand-alone & 8.5 & 8.5 & 7.1 & $\mathrm{~N} / \mathrm{A}$ & N/A \\
\hline
\end{tabular}

It is clear, from a simple inspection of Figure 1, that FiT rates are an important factor in the deployment of solar PV, but there are also a number of other factors that are equally important. The significant increase in uptake of solar PV over the last two years has also highlighted the growth in acceptance of the technology by consumers, with impending FiT changes causing peaks in installation. Critics have asked whether we have the physical capacity i.e. usable roof space, appropriate weather conditions as well as the desire and ability for individuals to install such technology. Without answering these questions it is hard to gauge the impact that this technology 
can realistically achieve. A mid-range estimate from the United Kingdom Energy Research Council (UKERC) states that this could be in the region of 16GWp of installed capacity by 2030 (Infield, 2007), although the UK Government has an aim of an extra 22GWp of solar PV by 2020 (Bennet, 2012).

Numerous authors have attempted to quantify rooftop PV potential across different regions, using a variety of techniques (Bergamasco and Asinari, 2011; Izquierdo et al., 2011; Kabir et al., 2010). Methods employed have largely depended upon three factors: the magnitude of the region being assessed; the availability of input data; and the studies' intended outcomes. In all cases authors have strived to quantify or compensate for key factors, such as available roof area, insolation and shading. The most rudimentary studies exploit relationships between population, building densities and suitable roof areas to calculate capacities across large areas (e.g. Izquierdo et al., 2008). These studies assume a group of simple representative buildings classifications and associated values. From this, global values can be extrapolated based upon readily available data. Whilst these studies can be useful in terms of alerting national policy makers to the potential of solar PV, the results produced are too broad to be of much use to individuals, regional policy makers and other key stakeholders. Improved methodologies, which are based on GIS-based studies or analysis of orthorectified satellite imagery (a geometrically corrected aerial photograph with uniform scale), have been able to yield more accurate results (Bergamasco \& Asinari, 2011).

The increasing availability of high resolution datasets has led to a surge in solar potential mapping. Consequently there are now numerous publically available mapping tools, such as IMBY (National Renewable Energy Laboratory, 2010), SEES (Seftigen, 2011) and SUN-AREA (SUN-AREA, 2011). These tools were quickly adopted by cities such as Boston, San Francisco, and Salt Lake City who produced publically available online maps to spur on potential installers (San Francisco Department of the Environment, 2007; City of Boston, 2008; Salt Lake City, 2010). The UK released its first online solar map for Bristol in 2012, produced by SUN-AREA in 2011, though this has received little public attention (Bristol City Council, 2012). An accompanying increase in the local marketing of resource assessments by UK companies, such as Geolnformation Group, is no doubt useful in helping individual and small groups of customers to make investment decisions in regard to installation of solar PV. However, it provides only a patchy picture of each area, which is insufficient in terms of policy making or cross-regional comparison.

Existing research into the socio-economic factors that determine uptake levels of solar PV also proves to be limited. Studies to date have only extended as far as survey and interview based experiments that are limited in terms of their scope. It is hard to gain a completely coherent view of the importance of individual socio-economic factors due to the wide range of aims amongst these 
studies. However, consensus found among a number of studies for influencing factors can be seen in Table 2. In addition, all of these studies stated that upfront costs represent a major barrier to the installation of solar PV. Two studies, Scarpa and Willis (2010) and Claudy et al. (2011) found that willingness-to-pay for a residential (2-4kWh) solar PV system was $£ 2831$ and $£ 3635$ respectively. However, the actual cost of installation is generally closer to $£ 6,000$ for a $3 \mathrm{kWp}$ solar PV unit (solarcentury, 2012). It has also been found that consumers expect payback periods to be between three and five years, whereas in reality the time horizon is more likely to be 10-15 years (Scarpa and Willis, 2010), as Government initiatives aim to provide a return of only $5 \%$ on investment (DECC, 2012c).

Table 2: Influencing socio-economic factors identified from the literature for the uptake of solar PV

\begin{tabular}{|l|l|}
\hline Influencing Socio-economic Factor & Reference \\
\hline Social Influences & Claudy et al., 2011; Jager, 2006 \\
\hline Level of education & Claudy et al., 2011; Sauter and Watson, 2007 \\
\hline Level of grant support & Keirstead, 2006; Candelise et al., 2010; Faiers and Neame, 2006 \\
\hline Age & Willis et al., 2011; Faiers and Neame, 2006; Elison, 2004 \\
\hline Environmental consciousness & Sauter and Watson, 2007; Jager, 2006 \\
\hline Knowledge of the technology & Elison, 2004; Sauter and Watson, 2007; Candelise et al., 2010 \\
\hline Social class & Elison, 2004; Caird et al., 2008 \\
\hline
\end{tabular}

Overall social acceptance is essential for the adoption of technologies such as solar PV, particularly in terms of microgeneration. Whilst the public may only be interested in the passive consent of large

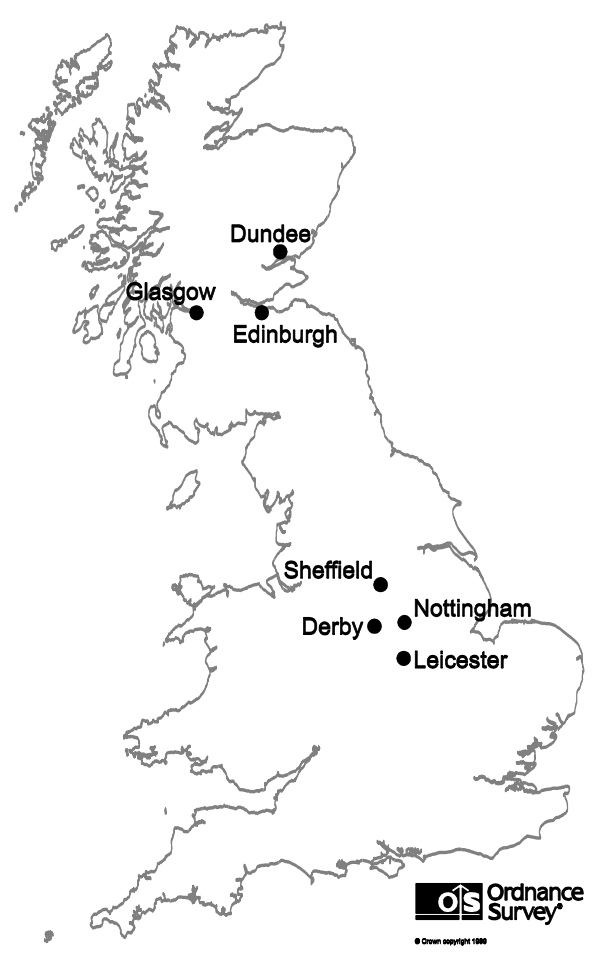

Figure 2: Location of seven cities analysed scale deployment of energy technologies, microgeneration requires active acceptance (Sauter and Watson, 2007). Therefore, it is necessary to understand the impact that socio-economic factors can have on the uptake of solar PV in order to inform policy in this area.

This article reports recent work to develop a methodology that integrates both physical capabilities and socioeconomic influences for the seven cities seen in Figure 2 in order to determine the realistic capacity that can be utilised. The cities chosen were a result of available data at the time of writing. A Solar City Indicator $(\mathrm{SCl})$ is calculated, which enables a ranking based on these factors, as well as an indication of each city's electricity demand that could potentially be met through the installation of solar PV. This data will be of use in assessing the effectiveness of UK policy regarding this 
technology and shows whether there are discrepancies in terms of regional variations.

\section{Methodology}

\subsection{Physical Capacity}

The physical capacity of each city was established using a GIS based methodology, employing ESRI's Solar Radiation Toolset (Environmental Systems Research Institute 2009), which exploits digital surface models (DSM) generated from Light Detection and Ranging (LiDAR) data. The DSM and a set of building footprint data were sourced for each city from Landmap ${ }^{1}$.The DSM for each city was matched with the building footprints, allowing the slope, aspect and annual incident insolation to be assessed for each rooftop. During this process a series of physical limits were imposed to restrict the evaluated insolation to areas where it would be feasible to install PV. These included:

- limiting the suitable area to the south facing component of roofs (i.e. aspect sits between 90 and $\left.270^{\circ}\right)$

- removing areas where insolation was less than $850 \mathrm{kWh} / \mathrm{m}^{2}$, as these were never likely to prove economic under conceivable tariffs or electricity prices

- $10 \%$ of rooftop area was removed to allow for chimneys, aerials and other rooftop obstructions that LiDAR data is too coarse to consistently capture

- limiting the suitable area to regions with slopes below $60^{\circ}$

The restriction on slope was partly included to limit inclusion of crests, areas where transitions between two levels were encountered (which would likely be shaded), and sharp curvatures. The analysis also made an underlying assumption that roofs displaying a low and consistent slope were flat planes and not curved surfaces.

The ArcGIS Area Solar Radiation tool employed "accounts for atmospheric effects, site latitude and elevation, steepness (slope) and compass direction (aspect), daily and seasonal shifts of the sun angle, and effects of shadows cast by surrounding topography" (Environmental Systems Research Institute 2009). However, the toolset does not account for weather and temperature. Fortunately, whilst regional temperature variations across the UK do exist, they are insufficient to cause a significant change in output, and can reasonably be ignored. The influence of weather was accounted for using a straightforward correction. A weather factor for each location was computed based upon Met Office data regarding the hours of direct sunlight received by each city (see

\footnotetext{
${ }^{1}$ Landmap is funded by the Joint Information Systems Committee (JISC) and provides geospatial data for use in academic research (Landmap, 2012).
} 
supplementary information). The resulting factor was applied to the GIS outputs, and results for a random selection of properties were compared with outputs from the European Union Joint Research Council (EU-JRC) model. The results showed relatively good agreement, with maximum differences in output of less than $10 \%$ and differences generally below $5 \%$. Some difference is to be expected owing to the variances in the morphological data of each city. The final output was a matrix of insolation incident on exploitable areas of each rooftop across each city.

For roofs of less than $200 \mathrm{~m}^{2}$ an alternative methodology was devised to tackle digital representation inaccuracies that result from the insufficient number of incident data points on smaller roofs. The methodology for smaller properties centred on extrapolating values typical to larger properties of the same building class in the same study area. Building classifications followed National Building Database criteria which categorise buildings based on age and structure type (The Geolnformation Group, 2010).

The potential output from small properties was estimated using the EU-JRC PVGIS model which required three inputs related to the buildings in the study areas, namely: the area of roof space available; the angle of the roof space; and the orientation of that roof space (EU-JRC, 2012).

Angles of slope for small property rooftops were estimated by identifying a characteristic slope for each building class from trends observed in large properties. The calculation of small property orientation distribution was again approximated using trends observed amongst different large property building classes. It was assumed that small properties would be arranged with a similar distribution of orientations to large properties, as both would be subject to the effects of defining features such as major rivers, motorways or coastlines. Finally the calculation of small property rooftop area suitable for a PV array was performed using building footprint data from Landmap. This figure was then corrected for the typical roof being only half south-facing and for the presence of chimneys, skylights and other roof obstacles with $10 \%$ of remaining roof space removed following Bergamasco and Asinari (2011). The EU-JRC PVGIS model tool takes into account insolation, weather patterns, topological shading, and system losses. An estimated correction for non-topography shading based on values suggested in Izquierdo et al. (2008) of $16 \%$ was applied to represent the impact of near-by trees and buildings.

The resultant outputs for large and small properties were used to determine the financial viability of available sites. This was done by computing the likely payback period based upon potential energy bill savings and subsidies. The energy bill savings were calculated using the average consumption of domestic properties in each city. This was added to the income from the export tariff and FiT. The 
cost of installation for each array was then divided by the annual income achieved by the array to provide a payback time in years.

$$
\text { Payback }=\frac{C_{\text {installation }}}{\mathrm{EBS}_{\text {Annual }}+\mathrm{ETI}_{\text {Annual }}+\text { FiT }_{\text {Annual }}}
$$

Where $\mathrm{C}_{\text {installation }}$ represents the cost of the installation, $\mathrm{EBS}_{\text {Annual }}$ the annual electricity bill saving, $\mathrm{ETI}_{\text {Annual }}$ the annual export tariff income and $\mathrm{FiT}_{\text {Annual }}$ the annual FiT income. The results were constructed to show viable generation for one year increments in payback period up to 25 years, which was the FiT payments lifetime at the time of writing.

Installation costs were adapted from quotes provided by the sources provided in the supplementary information section which were correct as of 09/11/2012:

Mid-ranging values were used for the $\mathrm{kWp}$ rating categories. Prices for larger installations were based upon rough estimates per kWp (listed below) obtained from communication with Anesco, a prominent UK-based energy services provider. Additional values for intermediary installation sizes were obtained by interpolation.

\subsection{Socio-economic Potential}

The first step in assessing the socio-economic potential was to determine which of the factors from the literature (Table 2) could be quantified for each city. Education levels of $4 / 5$ (degree level), environmental consciousness (represented by recycling rates) and higher social class all showed significant correlations with current solar PV installations per household, across twenty UK cities ( $p=$ $0.005, p<0.01$ and $p=0.001$ respectively). However, a strong correlation was found between social class and education level, and therefore, it was decided to remove social class from the analysis to prevent double counting.

Education level and environmental consciousness are considered to be factors that determine the desire of individuals to install solar PV. In addition, three ability factors were also included; mean income, proportion of houses/bungalows to flats and owner occupation. Income did not show a significant correlation with installed PV levels, however, this can be explained by the fact that under the FiT scheme prior to December 2011, a large number of "rent-a-roof schemes" were promoted. With favourable FiT rates it was profitable for companies to offer free solar panels and installation to customers in return for the resultant FiT payments. However, since the FiT rates have decreased these schemes have become less popular, and therefore it was decided that mean income should be included in the analysis. 
Data was collected (.

Table 3) from the following sources for the most recent year where full data was available:

- Education level, owner occupation, proportion houses/bungalows: Census 2001 (ONS, 2011; SCROL, 2011).

- Income: Survey of Personal Incomes 2007-2008 (ONS, 2010)

- Environmental consciousness, represented by percentage of household waste recycled: Local authority collection data 08-09 (Defra, 2011) and Waste Data Digest 11: 2009 (SEPA, 2011).

Table 3: Data obtained for socio-economic factors for each city

\begin{tabular}{|l|c|c|c|c|c|}
\hline & \multicolumn{3}{|c|}{ ABILITY } & \multicolumn{2}{c|}{ DESIRE } \\
\cline { 2 - 6 } & $\begin{array}{c}\text { Mean } \\
\text { Income (f) }\end{array}$ & $\begin{array}{c}\text { \% Houses/ } \\
\text { Bungalows }\end{array}$ & $\begin{array}{c}\text { \% Owner Occupied } \\
\text { Households }\end{array}$ & $\begin{array}{c}\text { \% Household } \\
\text { Waste Recycled }\end{array}$ & $\begin{array}{c}\text { \% Adult Population } \\
\text { with min Education } \\
\text { Level 4/5 }\end{array}$ \\
\hline Derby & 22400 & 87.33 & 69.24 & 40.6 & 17.73 \\
\hline Dundee & 20300 & 47.40 & 53.62 & 33.0 & 17.53 \\
\hline Edinburgh & 30400 & 40.88 & 68.57 & 27.1 & 32.84 \\
\hline Glasgow & 22400 & 47.40 & 48.54 & 18.1 & 17.94 \\
\hline Leicester & 19800 & 82.68 & 57.93 & 33.5 & 16.76 \\
\hline Nottingham & 20600 & 78.89 & 69.44 & 29.0 & 17.62 \\
\hline Sheffield & 22300 & 81.32 & 60.15 & 27.3 & 18.83 \\
\hline
\end{tabular}

The data for each factor was then normalised by assigning a value between 0 and 1 , using the below equation, to allow comparison between cities. The overall socio-economic indicator value is the result of the sum of the individual factors for each city.

$$
\frac{(\text { Factor Value - Minimum Value })}{\text { Difference between Max and Min }}
$$

Validation was provided through comparing values for the capacity of existing PV installations on a per capita basis for each city under the FiT scheme (ofgem, 2013), with the overall socio-economic indicator value. There is correlation between these values although it is not significant $(p=0.1)$. The reason for this is that Edinburgh has a low installed capacity for a high indicator value. If Edinburgh is removed then the correlation is highly significant $(p=0.01)$. It can be seen that the socio-economic indicator value clearly gives a good indication of likely uptake of solar PV in these cities, but cannot give a definitive answer as to whether cities will do so, as there may be underlying factors that cannot be accounted for, as is likely to be the case with Edinburgh.

It is acknowledged that quantifying socio-economic influences brings inherent complexities due to the interlinking of different factors and in some cases it is simply not possible to put a value on 
certain factors that may be important in overall decision making. Therefore the five factors analysed in this study had to be treated as dependent factors, although analysis looks at them separately in order to discover whether there are stand-out influences. This methodology serves as a baseline for assessing multiple areas.

\subsection{Solar City Indicator Calculation}

The $\mathrm{SCl}$ was calculated by multiplying financially viable output per capita estimations by the corresponding socio-economic indicator value for each city. Prior to this, the financially viable output was normalised by the relevant city's population to create a 'per capita' physical output calculation. This was performed to allow comparison of the physical solar resource and final $\mathrm{SCl}$ value across the different sized cities. This then permitted more detailed analysis of the impact of socio-economic effects on the overall results.

\section{Analysis}

The results for the physical and social sides of the study will first be presented separately and then brought together to form the SCl.

\subsection{Physical}

In all cities the maximum output that could be achieved under a 25 -year payback condition would meet a sizeable portion of the cities' energy demands (Figure 3). This figure ranged from 14 to $27 \%$ but even under more realistic payback time criteria, of ten years for example, between 5 and $11 \%$ of electricity demand could be met (excluding Glasgow).

\section{$30 \%$ of city's electricity demand met by viable rooftop PV}

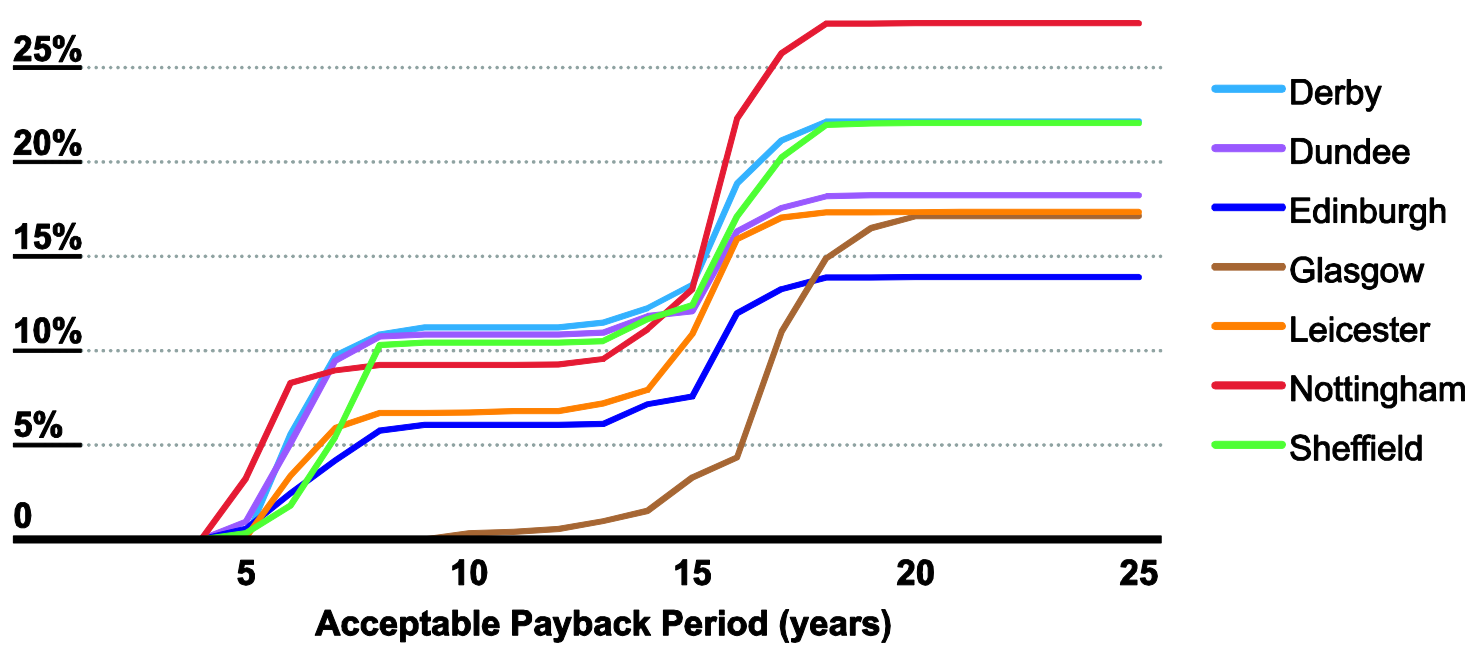

Figure 3: Percentage of electricity demand that can be met by financially viable rooftop PV 
Referring to Figure 4, which shows the data of Figure 3 normalised by population, under the shortest payback criteria Nottingham was the strongest performer although this only applied to payback criteria of four and five years. When the payback condition was between six and fifteen years Dundee performed strongest whilst under a payback criterion of 15 years or above Nottingham was again the best performing city. The Dundee building stock contains a number of very large warehouse properties, in proportion to its population; a reflection of its dockland heritage. Indeed, the dockland buildings are also aligned to the banks of the Firth of Tay meaning there are a number of very large south-facing roof slopes with exposure to significant solar radiation, which are not interrupted by obstructions or topographical features to the south.

$1400 \mathrm{kWh}$ per person per annum from viable rooftop PV

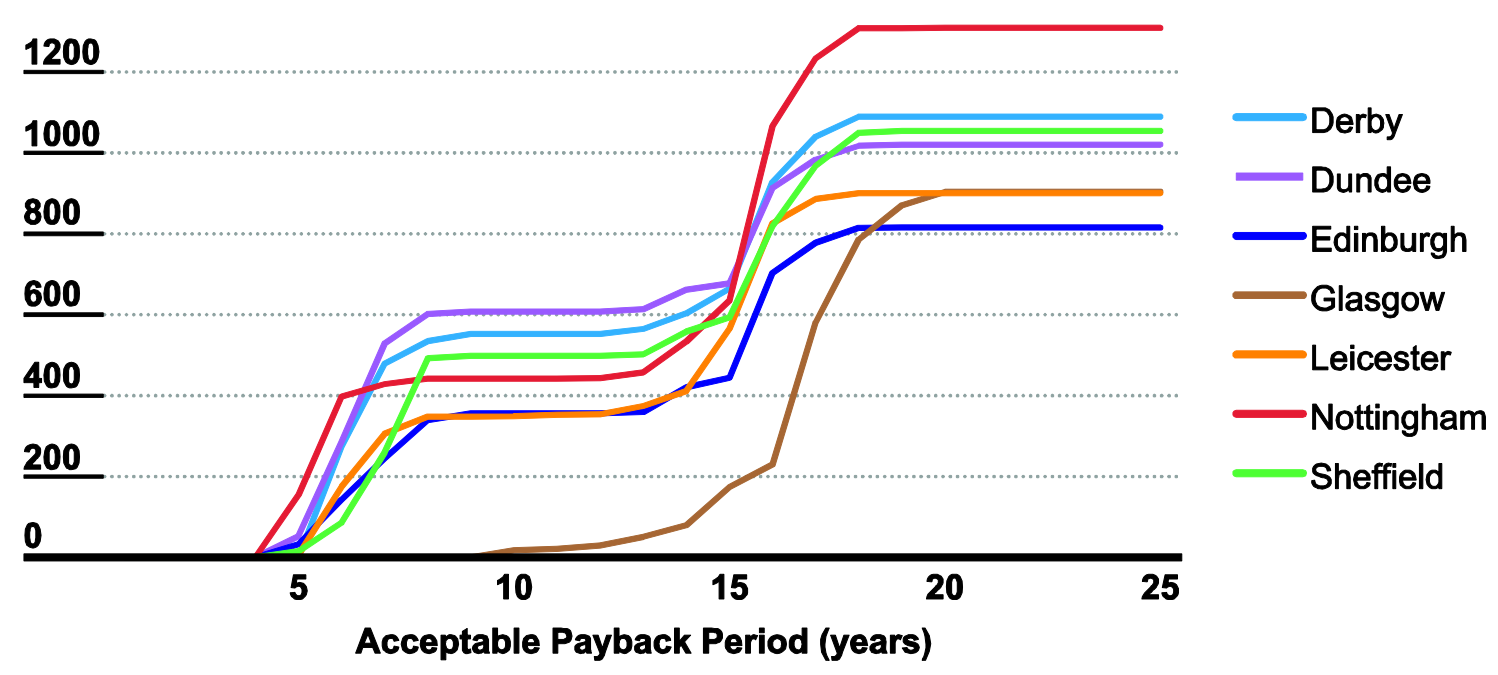

Figure 4: Predicted kWh output per person per annum from financially viable rooftop PV

Whilst Derby failed to rank highest in terms of output per capita for any payback criterion, the city was the second highest for payback periods ranging from 6 to 25 years. This shows that in the context of both large and small properties, the city is well-suited to PV technology.

Glasgow had the lowest viable output per capita until the payback criteria increased to 18 years with a burst in viability at 14 to 20 years payback period. The principal reason for this was Glasgow's high latitude and poor weather, which reduced available insolation at all properties. This results in few small scale properties achieving financial viability within an acceptable payback time. Larger properties can take advantage of certain economies of scale but still struggle to achieve acceptable payback periods.

The appearance of two plateaus in Figure 3 and Figure 4 stems from the differences in FiT rates and costs between small and large arrays. All small properties remain unviable until four years and their 
maximum viability is reached by eight years. This same pattern is repeated for large properties with little viability prior to 13 years and then a sudden increase in viability approaching 20 years. The exception to this range of payback periods was Glasgow where small arrays became viable after 9 to 18 years. Hence for small properties, the timescales calculated in this study fall within those described by Claudy et al. (2011) as acceptable to property owners (nine years) although they fall outside the 3 to 5 year payback requirement described in Scarpa and Willis (2010).

\subsection{Socio-economic}

It is evident from the results seen in Table 4 that it is Edinburgh, closely followed by Derby, which has the best potential for uptake of solar PV in terms of socio-economics. It is clear that Glasgow has a significantly lower potential than the other cities analysed. It is also apparent that there is not one factor that clearly contributes above the others, with each city having a differing mix of contributing factors.

Table 4: Socio-economic factors (normalised) with the overall socio-economic indicator value showing the sum of each factor for each city.

\begin{tabular}{|l|c|c|c|c|c|c|}
\hline City & $\begin{array}{c}\text { Environmental } \\
\text { Consciousness }\end{array}$ & $\begin{array}{c}\text { Education } \\
\text { Level }\end{array}$ & $\begin{array}{c}\text { Mean } \\
\text { Income }\end{array}$ & $\begin{array}{c}\text { Proportion } \\
\text { Houses }\end{array}$ & $\begin{array}{c}\text { Owner } \\
\text { Occupation }\end{array}$ & $\begin{array}{c}\text { Socio- } \\
\text { economic } \\
\text { Indicator } \\
\text { Value }\end{array}$ \\
\hline Derby & $\mathbf{1 . 0 0}$ & 0.06 & 0.25 & $\mathbf{1 . 0 0}$ & 0.99 & 3.30 \\
\hline Dundee & 0.66 & 0.05 & 0.05 & 0.14 & 0.24 & 1.14 \\
\hline Edinburgh & 0.40 & $\mathbf{1 . 0 0}$ & $\mathbf{1 . 0 0}$ & 0.00 & 0.96 & $\mathbf{3 . 3 6}$ \\
\hline Glasgow & 0.00 & 0.07 & 0.25 & 0.14 & 0.00 & 0.46 \\
\hline Leicester & 0.68 & 0.00 & 0.00 & 0.90 & 0.45 & 2.03 \\
\hline Nottingham & 0.49 & 0.05 & 0.08 & 0.82 & 1.00 & 2.43 \\
\hline Sheffield & 0.41 & 0.13 & 0.24 & 0.87 & 0.56 & 0.60 \\
\hline
\end{tabular}

Edinburgh benefits from high levels of education, mean income and owner occupation of homes, whilst Derby shows strong environmental consciousness, proportion of houses and owner occupation. The middling cities consist of Sheffield, Nottingham and Leicester. Generally three factors make up the potential for these cities; proportion of houses, environmental consciousness and owner occupation. Dundee has a lower potential, performing well on environmental consciousness but falling down on other factors, especially mean income and education level. Glasgow shows the weakest potential of the cities due to poor performance in all areas but particularly in environmental consciousness and owner occupation.

If the stages of innovation take place for solar PV as described by Rogers (2003) then some socioeconomic factors should become less important over time. The stages of innovation are as follows: 
- Innovators, who understand the complexity of the technology as well as having the financial ability to invest in it.

- Early adopters, who are the group with the most leadership in terms of roll out of new technology.

- Early majority, who make up a third of the system

- Late majority, who also make up about a third of the system but are dependent on the wider economic need and/or peer pressure.

- Laggards, who are suspicious of new technology and are often in a precarious economic position.

It is clear that we have now overcome the innovation stage, and with preferable FiT rates the early adoption stage seemed to progress rapidly towards the early majority. However, this has certainly slowed since the reduction in FiT rates. Moving into an early majority stage, decisions are based less on opinion leadership and therefore environmental consciousness is likely to become less important. Moving into the next stages where economic need dominates decision making, we can begin to see limiting factors. At this point it is likely that the ability factors will dominate decision making. In terms of income, Nottingham, Leicester and Dundee will be more constrained than most, with the lowest income levels. It is hoped by this point that the cost of installing PV will have reduced significantly to a more affordable rate, with the current trend of a $5 \%$ drop in residential system price (including installation costs) and a 7\% drop in commercial and industrial system prices between March 2011 and March 2012 (solarbuzz, 2012) supporting this assumption. If this continues to happen then the two limiting factors will be owner occupation and proportion of houses to flats. In terms of owner occupation the cities of Dundee, Glasgow and Leicester will suffer the most. Hopefully, this will also be less of a problem in the future with more encouragement for landlords to install solar PV. Therefore, the only truly limiting factor will be the proportion of houses to flats. The proportion of houses to flats is the factor that is most difficult to change in terms of policy. It is clear that the Scottish cites are severely hampered here compared to the English cities, with the worst performing English city significantly outperforming the best Scottish city. This is a result of the large number of tenement buildings present in these cities.

It should be noted that the later stages of innovation will only be achieved when almost all uncertainty is removed; therefore there is an important part for policy to play here. There is also potential for the laggards to be dealt with early, especially in the case of those that are in a precarious economic position through the use of PV on social housing as discussed later. 
It is important to remember that there are only seven cities analysed here and results are relative to each other. Whilst, generally the English cities sit around average for most of the factors analysed, it is the Scottish cities that show the most extreme difference to the British average. Both Dundee and Glasgow fall below average for all factors, significantly for proportion of houses and owner occupation with Glasgow also showing a particularly low result for environmental consciousness. Edinburgh also has significantly below average results for proportion of houses as well as environmental consciousness but to a lesser extent. However, Edinburgh performs significantly above average for education level and mean income.

\subsection{Solar City Indicator Results}

Because of the design of the methodology, when physical and socio-economic results are combined it is clear that socio-economic factors have a strong influence on the potential of each city (Figure 5). Due to Derby's strong physical capacity, as well as its very strong socio-economic potential; it has the highest $\mathrm{SCl}$ value across all payback periods greater than five years. Edinburgh has the second or third highest $\mathrm{SCl}$ across the payback periods even though it was towards the bottom in terms of physical capacity amongst the other cities. It is also evident that there is a significant drop in $\mathrm{SCl}$ for Glasgow and Dundee, which is unsurprising given their poor socio-economic performance.

\subsection{Solar City Indicator}

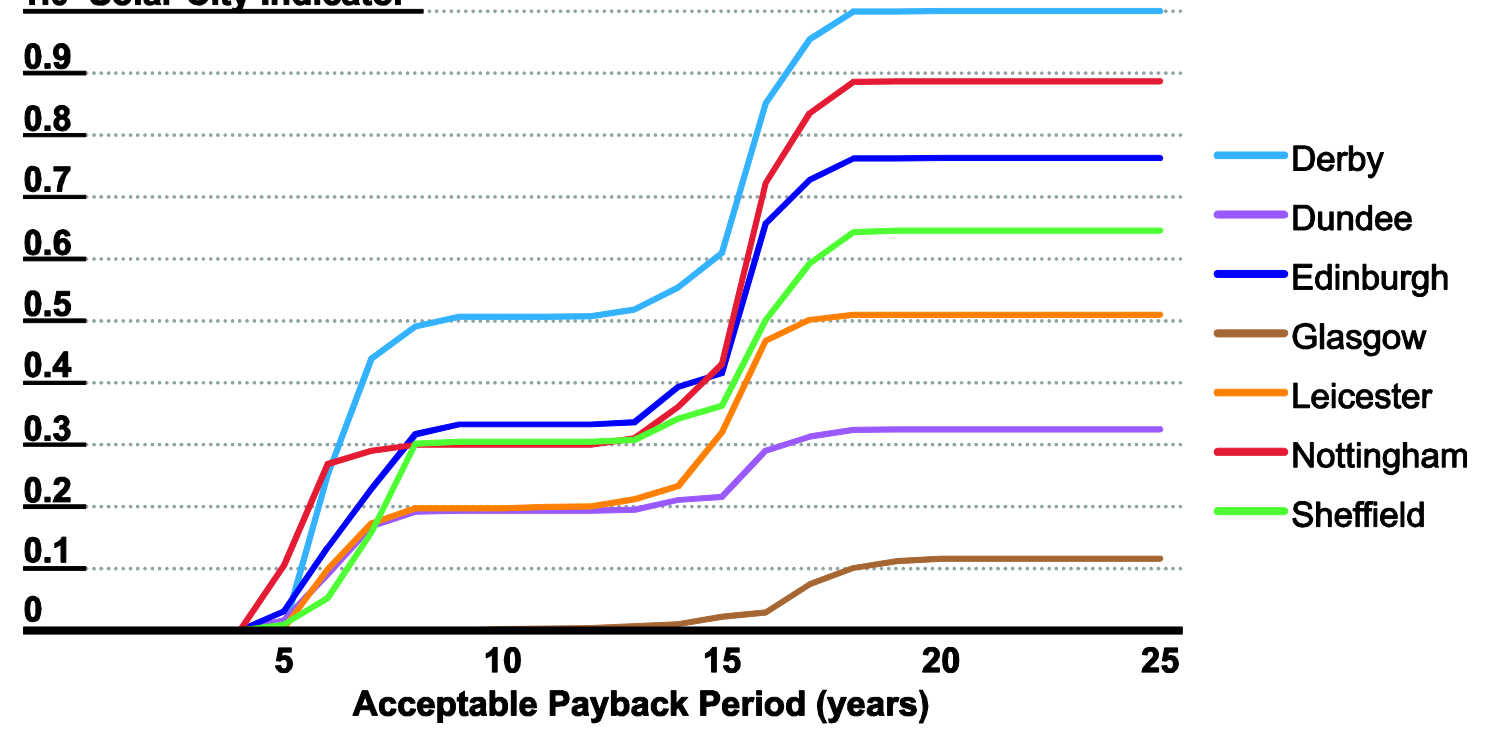

Figure 5: Solar City Indicator results with physical and socio-economic potential combined 


\subsection{Normalised Physical Indicator Values}

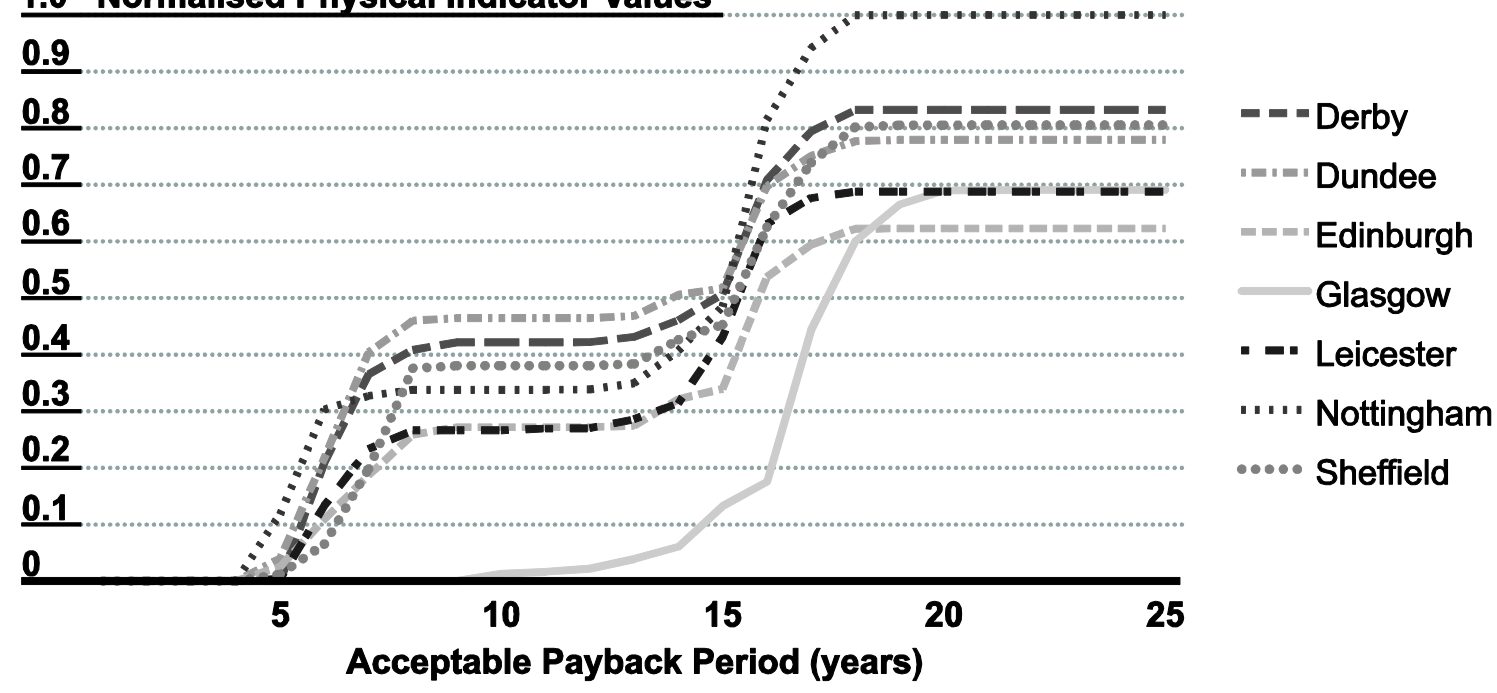

Figure 6: Normalised results for physical capacity

It is clear when the $\mathrm{SCl}$ (Figure 5) and normalised physical indicator values (Figure 6) are compared that the effect of the socio-economic results is to create a much larger spread of cities. This indicates that socio-economic effects strongly determine the uptake of solar PV across cities in general.

\section{Discussion}

The results show that a sizable percentage of all cities' electricity demand can be met by solar PV microgeneration. The results also show that despite changes to the FiT, there are a large number of viable sites across all cities that meet acceptable payback criteria.

The appearance of two plateaus in Figure 3 and Figure 4 for physical capacity stems from the differences in FiT rates and array costs between small and large arrays with small arrays contributing to the physical output figure over a shorter timescale than large arrays. This suggests that the FiT is now significantly skewed to aid investors in small PV installations rather than large. Whilst this shift could lead toward a more precisely targeted subsidy mechanism for small-scale PV microgeneration, it is also important to note the contribution of large properties in the present study roughly doubled the electricity generated in all cities. Whilst a key reason for the promotion of microgeneration is to affect a shift in behaviour and attitudes to energy, which may be best implemented by increasing the number of small arrays, the actual impact of PV in reducing carbon emissions and increasing energy security would be better served by a mechanism that could promote all scales of PV installations.

Whilst this study has shown that the FiT scheme may not be optimum in terms of exploiting the full benefits that could be seen for solar PV, there is one element of the FiT changes that has been shown to be correct. As part of consultation $2 \mathrm{~B}$ it was decided to reduce the payment period from 
25 years to 20 years. In this analysis it has been found that all installations viable under 25 year payback criteria were already viable within a 20 year payback period.

The assessment of economically viable physical capacity in the analysed cities has highlighted the importance of the FiT. However, there is a risk that there is no additional encouragement for the uptake of solar PV outside of the FiT. This study has shown the importance of socio-economic factors, with significant changes in the cities' potential and ranking. Before people even decide whether they can afford solar PV, they need to have the desire to install it in the first place. Whilst the desire factors that could be quantified in this analysis are limited, they do show that there are potentially large differences in a city's likelihood to install solar PV on the whole. For example, if just desire factors are taken into account, Edinburgh is significantly more likely to install PV than Glasgow.

The Government's Microgeneration Strategy (DECC, 2011) acknowledges that there are also a number of non-financial barriers that need to be addressed in order for technologies, such as solar PV, to be adopted by consumers. They put forward a number of actions with regard to both increasing the desire for uptake and making the process easier for people who wish to install. However, this study has highlighted that factors affecting uptake decisions can vary considerably among cities, and therefore a more localised approach is more likely to succeed in increasing uptake levels compared to nation-wide schemes.

Even when individuals do have a desire to install PV, there are a number of factors that will determine their ability to install. Firstly, people living in flats or businesses that do not own the roof space above are unlikely to be able to install solar panels. In this study it has been found that the four English cities are best placed in this respect with a higher than average proportion of houses/bungalows compared to flats. However, there is also the issue of whether people own their properties. Although there is the possibility of landlords installing solar PV on rented homes, it is more unlikely than for owner occupation. Edinburgh, Derby and Nottingham are the best placed cities for this analysis in this respect. The exception to this is where councils decide to install solar PV on social housing. For example, Nottingham City Council, in partnership with e.on, installed solar panels on 600 council owned homes (e.on, 2011). However, similar schemes from at least six local councils were put on hold when changes to the FiT were announced suggesting that such schemes are unlikely to continue in the future (Click Green, 2011).

Income also needs to be considered. Whilst FiT may provide a favourable rate of return, this is irrelevant to individuals who are unable to cover the upfront costs of installation. Under the FiT scheme prior to December 2011, rates were extremely favourable, which led to a large increase in 
the number of companies offering rent-a-roof schemes. This eliminated the need for individuals to cover the upfront costs of solar panels but still receive the benefits in terms of reduction in the cost of their electricity. With the new lower rates, it is less favourable for companies to offer such schemes and therefore, income has become a more important factor in determining uptake levels. From the cities that were analysed, there is likely to be some limitations in terms of income as all are below the British mean income. The exception to this is Edinburgh, which shows the greatest potential in terms of being able to cover these upfront costs.

Overall, the results show that there is not the regional difference that may be expected, particularly in terms of the physical capacity. As already mentioned, Dundee, the most northern city analysed, showed a fairly strong physical capacity due to a number of very large unshaded south-facing properties as a result of its dockland heritage. The importance of the type of buildings that are contained within a city was also highlighted in the socio-economic results. Whilst there was no clear regional divide between cities when all socio-economic factors are taken into account, there is a very clear divide between the Scottish cities and English cities when just proportion of houses/bungalows to flats is looked at. This can be attributed to a decision that dates back to the $19^{\text {th }}$ and early $20^{\text {th }}$ century when Scottish cities decided to build tenements, whereas in England back-to-back terraces were the preferred option (National Trust for Scotland, n.d.), which are more suitable for installation of PV on a per capita basis.

This study has also shown that current FiT rates discourage investment in large PV arrays in comparison to previous rates and those available in other countries, particularly Germany. In an attempt to make large scale installations financially viable alternative financing arrangements, such as power purchasing agreements with nearby industries, are becoming increasingly commonplace.

\section{Conclusion}

It is clear from this study that there is significant potential for solar PV microgeneration in the UK. However, the present research shows that the current FiT results in a double-plateaued chart of maximum output for payback criteria of 25 years and under, which represents the favouring of small over large arrays. Whilst this shows that the maximum viable output is reached by eight years for small properties, which is within the acceptable payback period for consumers according to the literature, it is clear that the FiT is significantly skewed to aid investment in these arrays rather than large arrays. With large installations showing roughly double the electricity generated in all cities analysed, this could be an oversight in terms of the potential for carbon reductions and energy security that these arrays could provide. 
This study has also demonstrated that policy should not just be limited to providing favourable FiT rates to capitalise on the available physical capacity but a focus must also be placed on the influence of a range of socio-economic factors. It is evident that a number of factors contribute to public ability and desire to install solar PV, which will also need to be addressed.

However, the most limiting factor found in both the socio-economic and physical analysis was the building stock of a city. It represents a factor that cannot be easily addressed by policy. For example, Dundee shows excellent potential to meet a significant proportion of its electricity demand due to the high number of large properties resulting from its dockland heritage and orientation to the Firth of Tay. However, Scottish cities on the whole are hampered by the preference for tenements, meaning there is a smaller potential output per person of solar PV generation. By comparison, Derby benefitted from socio-economic conditions more conducive to higher PV uptake as well as a topperforming physical solar resource.

The methodology presented can easily be applied to other locations using commonly available data and manageable computational requirements. The comparative nature of the method means that its application to a greater range of socio-economic contexts would enrich future studies as the overall understanding of social and physical factors develops. Interesting comparisons could then be made between countries and the macro-effects of their respective solar PV policies.

\section{Acknowledgements}

This work was financially supported by the Engineering and Physical Sciences Research Council through the University of Leeds Doctoral Training Centre in Low Carbon Technologies.

\section{References}

AEA (2011). The AEA Microgeneration Index, Available from:

http://www.aeat.com/microgenerationindex/ [Accessed on: 1 November 2011].

BENNETT, P. (2012) Barker once more quotes 22GW by 2020 solar 'ambition' [Online] Available from:

http://www.solarpowerportal.co.uk/news/barker once more quotes $22 \mathrm{gw}$ by 2020 sola $\underline{r}$ ambition 2356 [Accessed 12 November 2012]

BERGAMASCO, L. \& ASINARI, P. 2011. Scalable methodology for the photovoltaic solar energy potential assessment based on available roof surface area: Further improvements by orthoimage analysis and application to Turin (Italy). Solar Energy, 85, 2741-2756.

BRISTOL CITY COUNCIL. 2012. Bristol solar map [Online]. Available:

http://www.bristol.gov.uk/page/solar-energy [Accessed 16/02/2012] 
CAIRD, S., ROY, R. \& HERRING, H. 2008. Improving the energy performance of UK households: Results from surveys of consumer adoption and use of low- and zero-carbon technologies, Energy Efficiency, 1, 149-166

CANDELISE, C., GROSS, R. \& LEACH, M. A. (2010) Conditions for photovoltaics deployment in the UK: The role of policy and technical developments, Proceedings of the Institute of Mechanical Engineers, Part A: Journal of Power and Energy, 224:153.

CITY OF BOSTON. 2008. Boston Solar Map [Online]. Available: http://gis.cityofboston.gov/solarboston/\# [Accessed 02/05/2012]

CLAUDY, M.C., MICHELSEN, C. \& DRISCOLL, A.O. (2011) The diffusion of microgeneration technologies - assessing the influence of perceived product characteristics on home owners' willingness to pay, Energy Policy, 39, 1459-1469.

CLICK GREEN (2011) Councils warn Government to delay Feed in Tariff cuts as solar projects get axed, [Online] Available from: http://www.clickgreen.org.uk/news/national-news/122781councils-warn-government-to-delay-feed-in-tariff-cuts-as-solar-projects-get-axed.html. [Accessed 10 November 2011].

DECC, 2011. Microgeneration Strategy, Department of Energy \& Climate Change [Online] Available from: http://www.decc.gov.uk/assets/decc/11/meeting-energydemand/microgeneration/2015-microgeneration-strategy.pdf. [Accessed 30/10/2011].

DECC. 2012a. Weekly solar PV installation and capacity based on registration date, Department for Energy and Climate Change, [Online] Available from:

http://www.decc.gov.uk/en/content/cms/statistics/energy stats/source/fits/fits.aspx. [Accessed 05/10/2012].

DECC. 2012b. Current tariff tabe and Older tariff tables, Department of Energy and Climate Change [Online] Available from:

http://www.decc.gov.uk/en/content/cms/meeting energy/renewable ener/feedin tariff/fe edin tariff.aspx. [Accessed 30/09/2012].

DECC. 2012c. Government response to consulation on Comprehensive Review Phase 2B: Tariffs for non- $P V$ technologies and scheme administration issues, Department of Energy and Climate Change [Online] Available from:

http://www.decc.gov.uk/en/content/cms/meeting energy/renewable ener/feedin tariff/fit s review/fits review.aspx\#. [Accessed 30/09/2012].

DEFRA. 2011, Local authority data 08-09, Department for Environment, Food and Rural Affairs [Online] Available from: http://www.defra.gov.uk/statistics/environment/waste/wrfg23wrmsannual/. [Accessed 01/11/2011].

ELLISON, G. 2004. Renewable Energy Survey 2004: Draft summary report of findings, ORC International, London.

ENVIRONMENTAL SYSTEMS RESEARCH INSTITUTE. 2009. Understanding solar radiation analysis [Online] Available from:

http://webhelp.esri.com/arcgiSDEsktop/9.3/index.cfm?TopicName=Understanding_solar_ra diation_analysis [Accessed 19/11/2011]. 
e.on. 2011. 600 homes in Nottingham get solar panels. [Online] Available from: http://www.eonenergy.com/for-your-business/Sustainable-solutions/Latest-news/Newsarticles/Microgeneration/nottingham-city-council [Accessed 12/01/2012].

EU-JRC (2012) PV Estimation Utility, European Union Joint Research Council, http://re.jrc.ec.europa.eu/pvgis/apps4/pvest.php [Accessed 22/10/2012]

EUROPEAN COMMISSION JOINT RESEARCH CENTRE. 2007. Yearly total of global horizontal irradiation UK and Ireland [Online]. Available: http://re.jrc.ec.europa.eu/pvgis/countries/europe/g13y uk ie.png [Accessed 17/12/2011]

FAIERS A. \& NEAME, C. (2006) Consumer attitudes towards domestic solar power systems, Energy Policy, 34:14, 1797-1806.

IZQUIERDO, S., MONTAÑÉS, C., DOPAZO, C. \& FUEYO, N. 2011. Roof-top solar energy potential under performance-based building energy codes: The case of Spain. Solar Energy, 85, 208-213.

IZQUIERDO, S., RODRIGUES, M. \& FUEYO, N. 2008. A method for estimating the geographical distribution of the available roof surface area for large-scale photovoltaic energy-potential evaluations. Solar Energy, 82, 929-939.

JAGER, W. (2006) Stimulating the diffusion of photovoltaic systems: A behavioral perspective, Energy Policy, 34, 1935-1943.

JARDINE, C. \& BERGMAN, N. (2009) The status of the UK domestic PV market - a review of the impact of the low carbon buildings porgramme, Proceedings of the Photovoltaic Science Applications and Technology - PVSAT5, Glyndwr University.

KABIR, M. H., ENDLICHER, W. \& JÄGERMEYR, J. 2010. Calculation of bright roof-tops for solar PV applications in Dhaka Megacity, Bangladesh. Renewable Energy, 35, 1760-1764.

KEIRSTEAD, J (2006) The UK domestic photovoltaics industry and the role of central government, Energy Policy.

LANDMAP (2012) Landmap - Spatial Discovery. Landmap [Accessed 22/10/2012]

LEEDS SOLAR (2012) Leeds Solar PV Price Guide [ONLINE]. Available from: http://www.leedssolar.co.uk/price-guide [Accessed 14/12/2012]

NATIONAL RENEWABLE ENERGY LABORATORY. 2010. In My Backyard [Online]. Available: http://www.nrel.gov/eis/imby/ [Accessed 08/11/2011].

OFGEM (2013) Feed-in Tariff Installation Report 31 ${ }^{\text {st }}$ December 2012 [Online]. Available: http://www.ofgem.gov.uk/Pages/Morelnformation.aspx?docid=44\&refer=Sustainability/Env ironment/fits [Accessed 21/03/2013].

ONS. 2010. Survey of Personal Incomes 2007-2008, Office of National Statistics [Online]. Available from: http://www.hmrc.gov.uk/stats/income distribution/table-3-14-feb2010.pdf. [Accessed 30/10/2011].

ONS. 2011. Neighbourhood Statistics: 2001 Census, Office for National Statistics [Online]. Available: http://neighbourhood.statistics.gov.uk/dissemination/LeadPage [Accessed 30/10/2011]. 
ROGERS, E.M. (2003) Diffusion of Innovations, Fifth Edition, The Free Press, New York.

SALT LAKE CITY. 2010. Salt Lake City Solar Map [Online]. Available: http://www.slcgovsolar.com/ [Accessed 02/05/2012].

SAN FRANCISCO DEPARTMENT OF THE ENVIRONMENT. 2007. San Francisco Solar Map [Online]. Available: http://sf.solarmap.org/ [Accessed 02/05/2012].

SAUTER, R. AND WATSON, J. (2007). Strategies for the development of micro-generation: Implications for social acceptance, Energy Policy, 35, 2770-2779.

SCARPA, R. \& WILLIS, K. (2010) Willingness to pay for renewable energy: Primary and discretionary choice for British households' for micro-generation technologies, Energy Economics, 32, 129136.

SCROL. 2011. SCROL Analyser [Online] Available from:

http://www.scrol.gov.uk/scrol/common/home.jsp [Accessed 30/10/2011].

SEFTIGEN, K. 2011. The SEES-model [Online]. Available:

http://www.gvc.gu.se/Forskning/klimat/stadsklimat/gucg/software/sees/ [Accessed 18/12/2011].

SEPA. 2011. Waste Data Digest 11: Data Tables, Scottish Environmental Protection Agency [Online] Available from: http://www.sepa.org.uk/waste/waste data/waste data digest.aspx. [Accessed 01/11/2011].

SOLARBUZZ. 2012. Module Pricing. [Online] Available from http://www.solarbuzz.com/facts-andfigures/retail-price-environment/module-prices. [Accessed on 16/12/2012].

SOLAR CENTURY. 2012. Your Estimate: System Cost, [Online] Available from: http://www.solarcentury.co.uk/estimate/?postcode=Is2+8nx\&email=hollyaed\%40hotmail.co m. [Accessed 05/11/2012].

SOLAR ESSENCE. 2012. PV Price \& Feed-in-Tariff Calculator [ONLINE] Available from: http://www.solaressence.co.uk/domestic-pv/pv-price-\&-paybackcalculator.html?gclid=CLbst52VmrQCFczHtAodCAQAHQ [Accessed 14/12/2012].

SUN-AREA. 2011. SUN-AREA [Online]. Available: http://www.sun-area.net/ [Accessed 18/12/2011].

THE GEOINFORMATION GROUP. 2011. Solar Energy Mapping [Online]. Available:

http://www.geoinformationgroup.co.uk/products/solar-energy-mapping [Accessed 07/11/2011]

WILLIS, K., SCARPA, R., GILROY, R. \& HAMZA, N. (2011). Renewable energy adoption in an ageing population: Heterogeneity in preference for micro-generation technology adoption, Energy Policy, 39, 6021-6029. 